\title{
The Evolving Business Library: Introduction
}

\author{
MEG TRAUNER \\ Duke University \\ mtrauner@duke.edu
}

When "The Evolving Business Library" was selected as the theme for the 2019 Academic Business Library Directors' annual conference at Harvard Business School, no one was thinking of Charles Darwin. In nature, evolution is a slow process involving millions of minor changes that result in large effects on species over eons of time. In libraries, the changes are significant, and the rate of change is rapid--or at least they are experienced that way by librarians. Librarians find themselves stretching to adapt to their new environments and to help their users adapt too.

On the first day of the conference, trends and themes across ABLD libraries were analyzed and presented by Greg Fleming (University of Chicago). He and Carol Doyle (Northwestern University) have compiled these into a report for this issue of Ticker. As their report shows, changes in library environments are driving adaptations in libraries. Graduate business schools are adding new data analytics programs. Growing entrepreneurship centers provide opportunities for collaboration. Rising costs of textbooks and course packs are sparking creative solutions to the affordability issue for students. Other trends continue a steady evolution. Data continues to be at the top of faculty and student wish lists. Print collections continue to shrink while space is re-purposed. And always, when we speak about evolution, there is the struggle for resources.

Also in this issue, Hilary Craiglow and Kelly LaVoice (Vanderbilt University) describe how the the Walker Management Library at Vanderbilt University is meeting business students' emerging need for data literacy by offering an introductory-level course in data analytics and software computer programming. With expertise in evaluating, licensing and purchasing data sources, as well as deep experience in library instruction, business librarians at the Walker Management Library created a Software Computing Certificate program tailored to MBA students.

One innovation in scholarly communication is the Copyright First Responders system, developed by Kyle Courtney (Harvard University). Courtney formed a decentralized network of copyright experts at a number of cultural institutions in the U.S., including my own institution, Duke University. Librarians who work with faculty members and students on the front lines are provided immersive training to assess risk and to offer nimble support for basic copyright inquiries, while referring more problematic issues to university counsel.

Another evolving role for business librarians is providing systematic reviews, an innovative way to collaborate with research faculty. Ryan Splenda (Carnegie Mellon University) explains that librarians' expertise in information retrieval and database search strategies provides a functional advantage in yielding the complete set of relevant studies that make up the systematic review.

In 2015, Hilary Craiglow (Vanderbilt University) was asked to imagine the ideal academic business library and then given the opportunity to make it a reality. The comprehensive renovation of the Walker Management Library was completed during the summer of 2017 and the attractive and functional space is the jewel of Management Hall. 
Ticker: The Academic Business Librarianship Review, 4:2 (2020)

http://doi.org/10.3998/ticker.16481003.0004.201

(C)2020 Meg Trauner

In nature in a stable environment, evolution takes eons, but in times of dramatic change, species evolve more rapidly. In Spring 2020, libraries and universities are closed to on-site use by students and faculty, and librarians must provide collections, support and instruction exclusively online, a sudden and unprecedented change. Resourceful librarians are finding adaptive solutions to new problems and are sharing their ideas with colleagues. In this environment, rapid evolution is inevitable. 